\title{
AC 2009-1924: LESSONS LEARNED FROM TEACHING AND ASSESSMENT IN THE PHYSICS FOR ENGINEERS COURSE SEQUENCE
}

\section{Anca Sala, Baker College}

Dr. Sala is an Associate Professor and Chair of the Mechanical Engineering Department at Baker College in Flint, MI. She is actively involved in teaching and developing engineering curriculum, and leads the ABET accreditation activities in the department. She is a member of ASEE, ASME, and OSA.

\section{Raghu Echempati, Kettering University}

Dr. Echempati is a Professor of Mechanical Engineering at Kettering University, Flint, MI. His area of expertise is Design and CAE. He is a member of ASME, SAE and ASEE. 


\title{
Lessons Learned from Teaching and Assessment in the Physics for Engineers Course Sequence
}

\begin{abstract}
This paper is based on a continuation of a previous study undertaken by the authors, which looked at achievement of Student Learning Outcomes in one of the calculus-based introductory Physics courses taught to undergraduate Mechanical Engineering students. The paper presents results obtained from an expanded study that now includes all courses in the sequence. We are focusing on student learning outcomes that are pre-requisite knowledge to subsequent core engineering courses, and that relate directly to ABET required program outcomes. Special emphasis is placed on results from teaching and assessment in the Mechanics course. Analysis of data obtained over the course of two academic years yielded good insights into student learning, and recommendations to increase teaching effectiveness.
\end{abstract}

\section{Introduction}

In this paper we are looking at direct assessment of achievement of Student Learning Outcomes in the Introductory Physics sequence of courses taught to undergraduate Mechanical Engineering students at first author's institution. The structures of the academic year and of the Physics sequence are described in a previous paper ${ }^{1}$. The sequence consists of three courses: General Physics I covering Mechanics, General Physics II covering Electricity and Magnetism, and General Physics III covering Oscillations, Waves, Thermodynamics, Optics, and Modern Physics.

Direct assessment of student learning has become the preferred tool used by engineering programs across the country to demonstrate achievement of Program Outcomes, and increasingly also Program Educational Objectives at the recommendation of ABET, the engineering and technology accreditation body ${ }^{2,3}$. Several papers presented in recent years at the ASEE Annual Conferences have described valuable direct assessment methodologies applied to core engineering courses ${ }^{4,5}$. These methods utilize an Excel spreadsheet to keep track of graded student assignments and match those to Student Learning Outcomes in the course, and ultimately to the Program Outcomes. We have adopted a similar procedure to assess achievement in the Physics courses. In addition we are placing special emphasis on the Physics SLO's connected to future core engineering courses.

\section{Student Learning Outcomes in Introductory Physics Courses}

The knowledge and abilities we want our students to possess after completing the courses in their program are expressed in condensed form by the Student Learning Outcomes (SLO) associated with each course. The SLO's must support achievement of the a)-k) ABET Program Outcomes (PO), general to all engineering programs, as well as any outcomes specific to certain engineering disciplines. For example, for Mechanical Engineering, three more outcomes labeled 1)-n) can be defined. The a)-n) Program Outcomes for Mechanical Engineering are given in the Appendix. 
As can be observed by looking at the ABET a)-n) Program Outcomes, the SLO's from all the Physics courses support achievement of the following Program Outcomes: a), b), d), g), h), i), j), 1).

In addition, the Physics SLO's support achievement of SLO's in future core engineering courses. For example, the knowledge and abilities developed by students in the General Physics I course are an important pre-requisite for good understanding and ability in the engineering courses Statics, and Dynamics. Similarly, the SLO's of General Physics II support achievement of SLO's in the future Electric Circuit Analysis course. Tables 1 - 3 show the SLO's of the General Physics I, Statics, and Dynamics courses. Tables 4 and 5 show in matrix form the relationship between General Physics I SLO's, and Statics respectively Dynamics SLO's.

\section{Table 1. General Physics I (Mechanics) Student Learning Outcomes}

Students will be able to apply the concepts related to:

1. The SI system, dimensional analysis, scientific notation, significant digits.

2. The principles of kinematics, distance vs. displacement, speed vs. velocity, average and instantaneous velocity and equations of motion.

3. Vectors.

4. Newton's Laws of motion, mass and weight, and free-body diagrams.

5. Projectile motion.

6. Uniform circular motion.

7. Conservation of momentum.

8. Impulse, elastic collisions, and inelastic collisions.

9. Work and energy.

10. Potential energy, kinetic energy, energy conservation laws.

11. Center of mass.

12. Rotational motion, including, torque, angular momentum, rotational kinetic energy, and rotational inertia.

\section{Table 2. Statics Student Learning Outcomes}

Students will be able to:

1. Use general principles and problem solving techniques to solve engineering problems.

2. Solve operations with vectors such as force or position, resolve them into components, and project them along axes.

3. Use Cartesian vectors to solve problems involving the equilibrium of a particle for a concurrent coplanar (two-dimensional) force system and three-dimensional force system.

4. Solve for the moment of a force or a couple about a point and determine the resultants of a non-concurrent force system.

5. Use scalar methods, vector analysis and free body diagrams to solve problems involving the equilibrium of a rigid body for two- and three-dimensional force systems.

6. Solve for all the forces acting at the connections of trusses, frames, and machines (structures with pin-connected members), using the method of joints and the method of sections.

7. Solve for the location of center of gravity and center of mass for a system of particles and rigid bodies.

8. Solve for the moment of inertia for both an area and a body having a specific mass.

\section{Table 3. Dynamics Student Learning Outcomes}

Students will be able to:

1. Set up coordinate systems (rectangular/normal and tangential/cylindrical) to solve dynamic problems.

2. Select between the rectangular/normal and tangential/cylindrical coordinate systems.

3. Solve kinematics equations in problems involving rectilinear kinematics of a particle.

4. Construct and use position, velocity, and acceleration vs. time motion graphs.

5. Solve equations of motion to solve problems involving kinetics of a particle or system of particles.

6. Formulate the equations of work and energy to solve problems involving a particle or system of particles.

7. Formulate the equations of linear impulse and momentum or the conservation of linear momentum to solve problems involving a particle or a system of particles. 
8. Construct the coefficient of restitution and conservation of linear momentum to solve problems involving an impact of a particle or a system of particles.

9. Formulate the equations of moment of a force and angular momentum to solve problems involving a particle or a system of particles.

10. Formulate the equations of angular impulse and momentum or the conservation of angular momentum to solve problems involving a particle or a system of particles.

11. Formulate the equations of angular position, displacement, velocity, and acceleration to solve problems involving rotation of a rigid body about a fixed axis.

12. Formulate relative-motion analysis (translating and/or rotating axes) for position, velocity, and acceleration to solve problems on planar kinematics of a rigid body.

13. Solve for the moment of inertia of rigid body about any axis.

14. Formulate the equations of motion to solve problems involving planar kinetics of a rigid body.

15. Solve for the total kinetic energy of a rigid body involved in planar motion.

16. Solve for the work of a couple acting on a rigid body.

17. Formulate the equations of work and energy or conservation of energy to solve problems involving planar motion.

18. Formulate the equations of linear and angular momentum or the conservation of linear and angular momentum to solve problems involving planar motion of a rigid body.

Table 4. General Physics I vs. Statics SLO's. Table 5. General Physics I vs. Dynamics SLO’s.

\begin{tabular}{|l|l|l|l|l|l|l|l|l|}
\hline $\begin{array}{l}\text { GP I/Statics } \\
\text { SLO }\end{array}$ & 1 & 2 & 3 & 4 & 5 & 6 & 7 & 8 \\
\hline 1 & $\mathrm{x}$ & & & & & & & \\
\hline 2 & $\mathrm{x}$ & & & & & & & \\
\hline 3 & $\mathrm{x}$ & $\mathrm{x}$ & $\mathrm{x}$ & & & & & \\
\hline 4 & $\mathrm{x}$ & $\mathrm{x}$ & & & & & \\
\hline 5 & & & & & & & & \\
\hline 6 & & & & & & & & \\
\hline 7 & $\mathrm{x}$ & & & & & & & \\
\hline 8 & & & & & & & & \\
\hline 9 & $\mathrm{x}$ & & & & & & & \\
\hline 10 & $\mathrm{x}$ & & & & & & & \\
\hline 11 & $\mathrm{x}$ & & & & & & $\mathrm{x}$ & \\
\hline 12 & $\mathrm{x}$ & & $\mathrm{x}$ & $\mathrm{x}$ & $\mathrm{x}$ & & & $\mathrm{x}$ \\
\hline
\end{tabular}

\begin{tabular}{|l|l|l|l|l|l|l|l|l|l|l|l|l|l|l|l|l|l|l|}
\hline $\begin{array}{l}\text { GP I/ Dynamics } \\
\text { SLO }\end{array}$ & 1 & 2 & 3 & 4 & 5 & 6 & 7 & 8 & 9 & 1 & 1 & 1 & 1 & 1 & 1 & 1 & 1 & 1 \\
\hline 1 & & & & & & & & & & & & & & & & & & \\
\hline 2 & & & $\mathrm{x}$ & $\mathrm{x}$ & $\mathrm{x}$ & & & & & & & & & & & & & \\
\hline 3 & & & & & & & & & & & & & & & & & & \\
\hline 4 & & & & & & & & & & & & & & & & & & \\
\hline 5 & & & & & & & & & & & & & & & & & & \\
\hline 6 & & & & & & & & & & & $\mathrm{x}$ & & & & & & & \\
\hline 7 & & & & & & & $\mathrm{x}$ & & & & & & & & & & & \\
\hline 8 & & & & & & & & & & & & & & & & & \\
\hline 9 & & & & & & $\mathrm{x}$ & & & & & & & & & & & $\mathrm{x}$ & \\
\hline 10 & & & & & & & & & & & & & & & & & & \\
\hline 11 & & & & & $\mathrm{x}$ & & & & & & & & & & & & & \\
\hline 12 & & & & & & & & & $\mathrm{x}$ & & $\mathrm{x}$ & & $\mathrm{x}$ & & $\mathrm{x}$ & & & \\
\hline
\end{tabular}

The Student Learning Outcomes for the General Physics II course are as follows:

Table 6. SLO's of General Physics II (Electricity and Magnetism)

Students will be able to apply the concepts related to:

1. Electric charge, conductors, insulators and semi-conductors, and Coulomb's Inverse Square Law.

2. Electric field.

3. Gauss's Law including electric field lines, flux, electrostatic equilibrium.

4. Electric potential, potential difference, the relationship between potential and electric field.

5. Electrostatic energy, capacitance.

6. Capacitance of different types of capacitor.

7. Electric current, potential difference, resistance including Ohm's law, electric power.

8. Series and parallel combination of resistors in electrical circuits.

9. Magnetic force on moving charges and electric current.

10. Biot-Savart Law and Ampere's Law.

11. Electromagnetism and Faraday's law, including motional emf. 


\section{Direct Assessment Results for General Physics I and General Physics II Courses}

Assessment tools utilized include Homework, Quizzes, Laboratory Reports, Midterm Exam, and Final Exam. While all tools are used to assess achievement of SLO's, for brevity we discuss in the following only the results from Final Exams from the 2006-07 and 2007-08 academic years, and Midterm Exams from the 2007-08 academic year.

Tables 7 and 8 show the individual student results from academic year 2007-08 for General Physics I, and General Physics II respectively.

Table 7. General Physics I Individual Student Results.

\begin{tabular}{|c|c|c|c|c|c|c|c|c|c|c|c|c|c|c|c|c|c|}
\hline \multirow{2}{*}{$\begin{array}{l}2007-08 \\
\text { Student ID }\end{array}$} & \multicolumn{5}{|c|}{ Midterm Exam } & \multicolumn{12}{|c|}{ Final Exam } \\
\hline & SLO2 & SLO3 & SLO4 & SLO5 & SLO6 & SLO1 & SLO2 & SLO3 & SLO4 & SLO5 & SLO6 & SLO7 & SLO8 & SLO9 & SLO10 & SLO11 & SLO12 \\
\hline Max score & 30 & 30 & 40 & 30 & 20 & 10 & 30 & 30 & 40 & 10 & 40 & 10 & 35 & 35 & 10 & 10 & 40 \\
\hline Student 1 & 30 & 23 & 38 & 30 & 13 & 10 & 26 & 27 & 35 & 10 & 12 & 8 & 26 & 33 & 8 & 10 & 38 \\
\hline Student 2 & 30 & 28 & 37 & 30 & 20 & 10 & 25 & 30 & 40 & 10 & 40 & 5 & 19 & 35 & 10 & 10 & 40 \\
\hline Student 3 & 11 & 25 & 27 & 11 & 1 & 2 & 15 & 25 & 20 & 7 & 9 & 5 & 10 & 22 & 0 & 8 & 13 \\
\hline Student 4 & 30 & 28 & 40 & 30 & 20 & 10 & 30 & 30 & 37 & 10 & 40 & 10 & 33 & 35 & 10 & 10 & 31 \\
\hline Student 5 & 25 & 24 & 40 & 22 & 2 & 10 & 15 & 2 & 16 & 10 & 7 & 5 & 10 & 27 & 0 & 10 & 17 \\
\hline Student 6 & 30 & 30 & 40 & 30 & 20 & 10 & 23 & 23 & 35 & 10 & 24 & 5 & 23 & 35 & 0 & 10 & 40 \\
\hline Student 7 & 30 & 28 & 37 & 30 & 17 & 10 & 30 & 30 & 37 & 10 & 22 & 5 & 33 & 35 & 10 & 10 & 33 \\
\hline Student 8 & 20 & 30 & 33 & 20 & 19 & 10 & 22 & 25 & 25 & 10 & 25 & 10 & 33 & 23 & 0 & 10 & 32 \\
\hline Student 9 & 21 & 18 & 40 & 21 & 10 & 5 & 20 & 25 & 30 & 10 & 10 & 5 & 10 & 23 & 2 & 10 & 29 \\
\hline Student 10 & 27 & 28 & 40 & 27 & 20 & 10 & 30 & 30 & 29 & 10 & 23 & 10 & 20 & 22 & 0 & 10 & 16 \\
\hline Student 11 & 25 & 26 & 37 & 22 & 6 & 5 & 23 & 30 & 33 & 10 & 20 & 5 & 16 & 25 & 5 & 10 & 32 \\
\hline Student 12 & 21 & 23 & 40 & 18 & 17 & 5 & 17 & 27 & 31 & 10 & 12 & 5 & 25 & 35 & 7 & 10 & 23 \\
\hline Student 13 & 10 & 13 & 30 & 17 & 3 & 5 & 0 & 0 & 27 & 1 & 17 & 5 & 11 & 25 & 0 & 10 & 12 \\
\hline Average & 23.8 & 24.9 & 36.8 & 23.7 & 12.9 & 7.8 & 21.2 & 23.4 & 30.4 & 9.1 & 20.1 & 6.4 & 20.7 & 28.8 & 4.0 & 9.8 & 27.4 \\
\hline $\begin{array}{l}\text { Percent } \\
\text { average }\end{array}$ & 79 & 83 & 92 & 79 & 65 & 78 & 71 & 78 & 76 & 91 & 50 & 64 & 59 & 82 & 40 & 98 & 68 \\
\hline
\end{tabular}

Table 8. General Physics II Individual Student Results.

\begin{tabular}{|c|c|c|c|c|c|c|c|c|c|c|c|c|c|c|c|c|}
\hline \multirow{2}{*}{$\begin{array}{l}2007-08 \\
\text { Student ID }\end{array}$} & \multicolumn{5}{|c|}{ Midterm Exam } & \multicolumn{11}{|c|}{ Final Exam } \\
\hline & SLO1 & SLO2 & SLO3 & SLO5 & SLO7 & SLO1 & SLO2 & SLO3 & SLO4 & SLO5 & SLO6 & SLO7 & SLO8 & SLO9 & SLO10 & SLO11 \\
\hline Max score & 40 & 20 & 20 & 40 & 40 & 10 & 20 & 20 & 40 & 30 & 10 & 60 & 20 & 40 & 20 & 30 \\
\hline Student 1 & 27 & 10 & 10 & 27 & 28 & 10 & 19 & 5 & 28 & 25 & 10 & 37 & 15 & 28 & 20 & 20 \\
\hline Student 2 & 22 & 10 & 10 & 18 & 17 & 10 & 19 & 5 & 13 & 15 & 10 & 37 & 10 & 15 & 16 & 22 \\
\hline Student 3 & 28 & 0 & 10 & 31 & 19 & 10 & 19 & 7 & 2 & 9 & 7 & 36 & 17 & 31 & 10 & 29 \\
\hline Student 4 & 32 & 11 & 10 & 37 & 37 & 10 & 20 & 13 & 16 & 27 & 2 & 46 & 15 & 30 & 13 & 13 \\
\hline Student 5 & 13 & 10 & 10 & 36 & 40 & 10 & 19 & 17 & 31 & 14 & 10 & 41 & 15 & 25 & 20 & 21 \\
\hline Student 6 & 0 & 0 & 0 & 0 & 0 & 10 & 10 & 5 & 21 & 11 & 2 & 46 & 13 & 28 & 4 & 20 \\
\hline
\end{tabular}




\begin{tabular}{|c|c|c|c|c|c|c|c|c|c|c|c|c|c|c|c|c|}
\hline Student 7 & 5 & 0 & 10 & 24 & 15 & 2 & 19 & 15 & 15 & 11 & 7 & 29 & 7 & 17 & 8 & 14 \\
\hline Student 8 & 23 & 0 & 10 & 24 & 37 & 10 & 20 & 15 & 17 & 27 & 10 & 46 & 12 & 29 & 20 & 22 \\
\hline Student 9 & 33 & 17 & 20 & 39 & 40 & 10 & 20 & 13 & 15 & 27 & 10 & 53 & 14 & 29 & 20 & 22 \\
\hline Student 10 & 40 & 20 & 20 & 36 & 38 & 10 & 20 & 20 & 27 & 27 & 10 & 60 & 20 & 40 & 18 & 22 \\
\hline Student 11 & 26 & 4 & 10 & 25 & 38 & 2 & 13 & 17 & 20 & 19 & 2 & 45 & 15 & 31 & 10 & 22 \\
\hline Student 12 & 27 & 10 & 5 & 18 & 34 & 10 & 17 & 20 & 12 & 2 & 2 & 32 & 12 & 10 & 0 & 29 \\
\hline Student 13 & 27 & 2 & 0 & 19 & 4 & 10 & 18 & 5 & 14 & 18 & 2 & 36 & 12 & 29 & 10 & 29 \\
\hline Student 14 & 29 & 6 & 5 & 36 & 40 & 10 & 19 & 5 & 30 & 28 & 10 & 39 & 11 & 9 & 18 & 21 \\
\hline Student 15 & 26 & 1 & 20 & 35 & 37 & 10 & 15 & 13 & 30 & 28 & 10 & 46 & 15 & 24 & 12 & 20 \\
\hline Student 16 & 35 & 20 & 20 & 40 & 40 & 10 & 20 & 20 & 39 & 30 & 2 & 60 & 20 & 39 & 20 & 29 \\
\hline Student 17 & 29 & 0 & 0 & 12 & 11 & 10 & 20 & 15 & 9 & 10 & 7 & 25 & 8 & 4 & 9 & 12 \\
\hline Student 18 & 33 & 5 & 20 & 38 & 39 & 10 & 15 & 15 & 22 & 29 & 7 & 46 & 12 & 28 & 10 & 14 \\
\hline Student 19 & 34 & 15 & 0 & 36 & 29 & 10 & 20 & 15 & 32 & 29 & 10 & 46 & 15 & 17 & 12 & 19 \\
\hline Student 20 & 15 & 2 & 0 & 21 & 30 & 10 & 20 & 20 & 24 & 29 & 10 & 44 & 11 & 33 & 16 & 20 \\
\hline Student 21 & 20 & 5 & 10 & 7 & 9 & 10 & 19 & 13 & 25 & 24 & 10 & 46 & 15 & 18 & 13 & 15 \\
\hline Student 22 & 18 & 0 & 20 & 17 & 20 & 10 & 20 & 17 & 22 & 27 & 10 & 46 & 15 & 31 & 12 & 19 \\
\hline Student 23 & 26 & 17 & 20 & 27 & 39 & 10 & 17 & 15 & 23 & 25 & 10 & 46 & 15 & 24 & 12 & 13 \\
\hline Student 24 & 18 & 0 & 0 & 8 & 5 & 10 & 19 & 13 & 0 & 8 & 10 & 22 & 15 & 11 & 10 & 20 \\
\hline Student 25 & 40 & 6 & 8 & 38 & 39 & 10 & 19 & 7 & 36 & 28 & 10 & 46 & 7 & 30 & 16 & 29 \\
\hline Student 26 & 5 & 0 & 20 & 36 & 34 & 10 & 19 & 17 & 21 & 21 & 10 & 46 & 12 & 19 & 12 & 12 \\
\hline Student 27 & 18 & 0 & 5 & 16 & 2 & 10 & 19 & 15 & 17 & 28 & 10 & 33 & 10 & 22 & 1 & 12 \\
\hline Student 28 & 0 & 0 & 0 & 0 & 0 & 10 & 19 & 13 & 13 & 14 & 10 & 48 & 15 & 28 & 19 & 29 \\
\hline Student 29 & 33 & 0 & 20 & 36 & 36 & 10 & 15 & 13 & 8 & 24 & 10 & 38 & 15 & 32 & 9 & 20 \\
\hline Average & 23.5 & 5.9 & 10.1 & 25.4 & 26.1 & 9.4 & 18.2 & 13.2 & 20.1 & 21.2 & 7.9 & 42.1 & 13.4 & 24.5 & 12.8 & 20.3 \\
\hline $\begin{array}{l}\text { Percent } \\
\text { average }\end{array}$ & 59 & 29 & 51 & 64 & 65 & 94 & 91 & 66 & 50 & 71 & 79 & 70 & 67 & 61 & 64 & 68 \\
\hline
\end{tabular}

The final result for achievement of each individual SLO is obtained by weighted average of all assessment tools mentioned above (Homework, Quizzes, Lab Reports, Midterm, and Final Exam). However, out of all the assignments the Midterm and Final Exam have the most weight, so that considering only these two tools, or even only the Final Exam can provide relevant information about student learning in the course.

The target goal we have adopted is to have an average achievement of $70 \%$ or better for each SLO. The cells in red in Tables 7, and 8 reflect the SLO's where the percent average is less than $70 \%$.

A similar table is created for each course section, each time the course is taught. While these tables hold detailed information per student, the averaged data for the entire class is further used to create year-to-year comparisons such as the ones in Figures 1, and 2 below. 


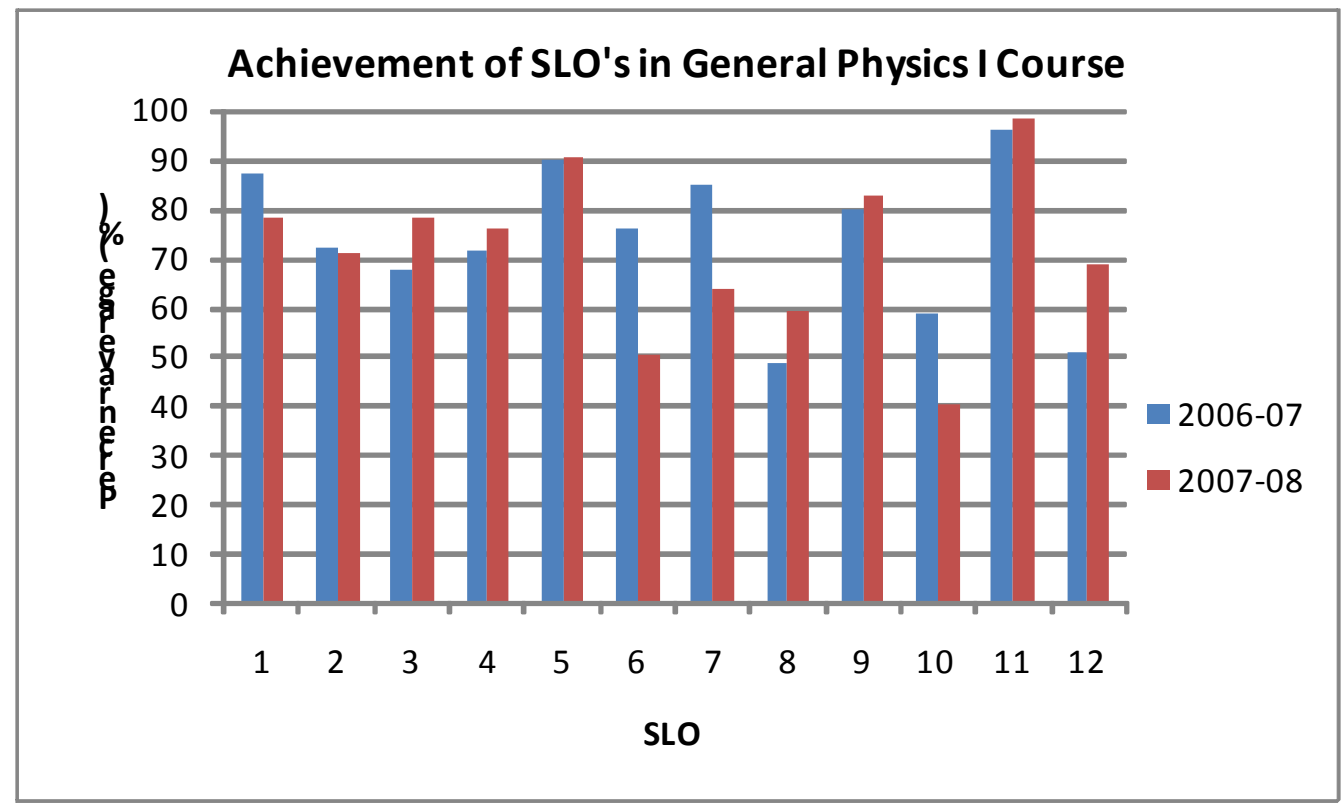

Figure 1. Year-to-year comparison of SLO achievement in the General Physics I course.

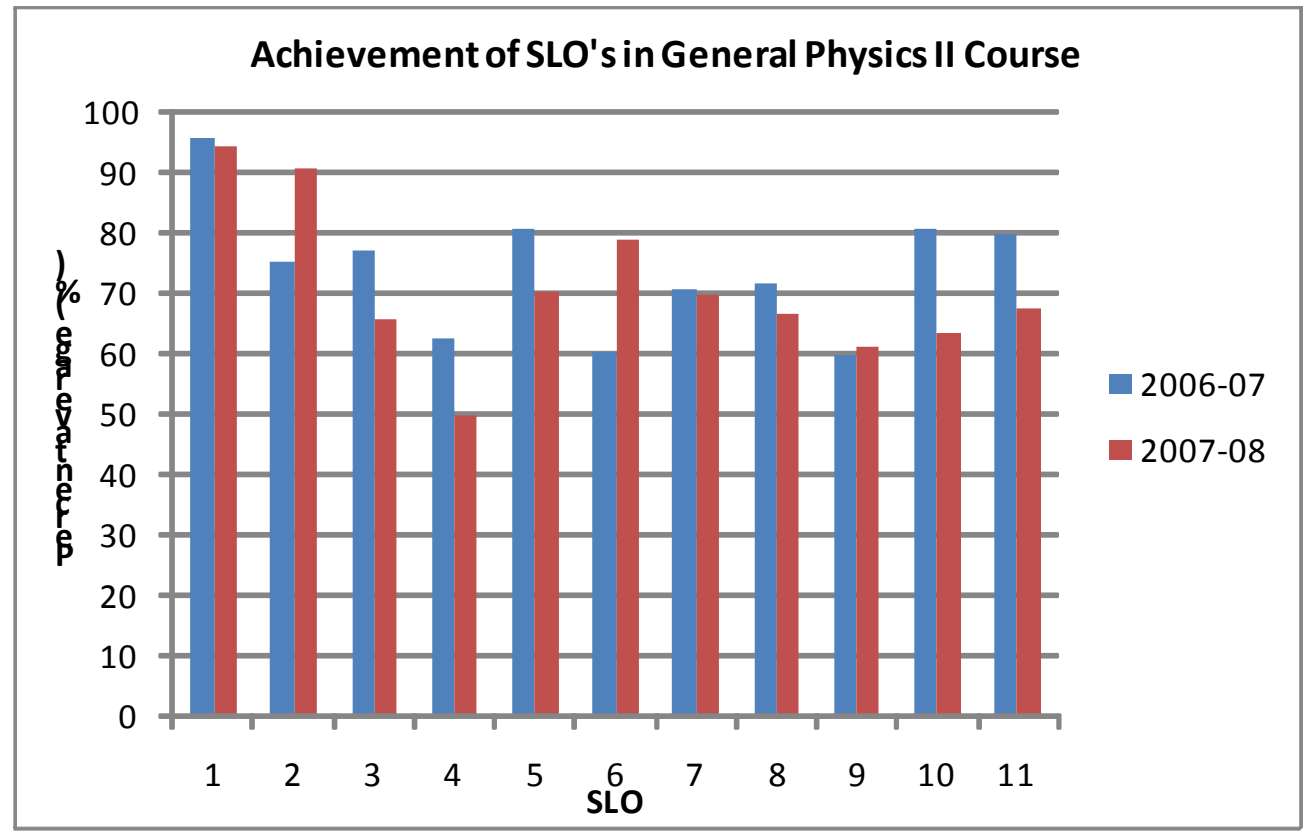

Figure 2. Year-to-year comparison of SLO achievement in the General Physics II course.

The Tables and bar graphs provided as examples allow for meaningful interpretation of the results. SLO's with lower than desired achievement trigger analysis in faculty meetings to understand the issues students might have with the associated topics. The consistency in low achievement in certain SLO's shown by the year-to-year analysis is another flag which requires faculty attention. For example SLO's 8 ("Impulse, elastic collisions, and inelastic collisions"), and 10 ("Potential energy, kinetic energy, energy conservation laws") are consistently in the range $40 \%-60 \%$ in both academic years. These topics require more focused attention on the part 
of the professor in the following year. A similar situation can be seen with SLO's 4 ("Electric potential, potential difference, the relationship between potential and electric field"), and 9 ("Magnetic force on moving charges and electric current") in General Physics II.

\section{Conclusions}

We presented a methodology for direct assessment of achievement of SLO's in the Mechanics, and the Electricity and Magnetism courses from the General Physics sequence taught to undergraduate Mechanical Engineering students. This systematic approach is helpful in uncovering student learning difficulties, providing for meaningful interpretation of the results and easy year-to-year comparison. By applying this method also to all core engineering courses, the data collected and analyzed is very useful for ABET accreditation.

Once the methodology is in place and data is gathered for a large enough population of students spread over several academic years, teaching adjustments can be tested, as well as improvements in the assessment method itself, such as careful design of the exam questions to correctly reflect the breadth and difficulty of each topic covered by the course.

\section{Bibliography}

1. A.L. Sala, R. Echempati, "Direct Assessment of Student Learning Outcomes in Physics for Engineers Courses", 2008 ASEE Annual Conference and Exposition, paper AC2008-923.

2. Rogers, G., "Assessment 101: Direct or Indirect Measures? Are We Asking the Right Question?" Community Matters, ABET, Inc., Nov. 2007.

3. J. Shaeiwitz, D. Briedis, "Direct Assessment Measures", 2007 ASEE Annual Conference and Exposition, paper AC2007-127.

4. E. Rodriguez-Marek, M.S. Koh, C. Talarico, "Connecting the Dots in Assessment: from Course Student Learning Objectives to Educational Program Outcomes to ABET Assessment”, 2008 ASEE Annual Conference and Exposition, paper AC2008-316.

5. H. Gurocak, "Direct Measures for Course Outcomes Assessment for ABET Accreditation", 2008 ASEE Annual Conference and Exposition, paper AC2008-778.

\section{Appendix}

ABET Program Outcomes for all engineering programs a)-k), and for Mechanical Engineering specialty 1)-n).

a) An ability to apply knowledge of mathematics, science, and engineering.

b) An ability to design and conduct experiments, as well as to analyze and interpret data.

c) An ability to design a system, components, or process to meet desired needs.

d) An ability to function on multi-disciplinary teams.

e) An ability to identify, formulate and solve engineering problems.

f) An understanding of professional and ethical responsibility.

g) An ability to communicate effectively.

h) The broad education necessary to understand the impact of engineering solutions in a global and societal context. 
i) A recognition of the need for, and an ability to engage in lifelong learning.

j) A knowledge of contemporary issues.

k) An ability to use the techniques, skills, and modern engineering tools necessary for engineering practice.

1) Knowledge of chemistry and calculus-based physics with depth in at least one.

m) The ability to apply advanced mathematics through multivariate calculus and differential equations; familiarity with statistics and linear algebra.

n) The ability to work professionally in both thermal and mechanical systems areas including the design and realization of such systems. 